\title{
Different methods for inducing adipose-derived stem cells to differentiate into Schwann-like cells
}

\author{
Songtao $\mathrm{Gao}^{1}$, Yan Zheng ${ }^{2}$, Qiqing $\mathrm{Cai}^{1}$, Xuejian $\mathrm{Wu}^{3}$, Weitao $\mathrm{Yao}^{1}$, Jiaqiang Wang ${ }^{1}$
}

\author{
'Department of Orthopedics, The Affiliated Tumor Hospital of Zhengzhou University, \\ Zhengzhou, China \\ 2Department of Radiology, The First Affiliated Hospital of Zhengzhou University, \\ Zhengzhou, China \\ ${ }^{3}$ Department of Orthopedics, The First Affiliated Hospital of Zhengzhou University, \\ Zhengzhou, China
}

Submitted: 16 July 2013

Accepted: 26 August 2013

Arch Med Sci 2015; 11, 4: 886-892

DOI: 10.5114 /aoms.2015.53310

Copyright @ 2015 Termedia \& Banach

\section{Abstract}

Introduction: The aim of the study was to explore an effective method to induce adipose-derived stem cells (ADSCs) to differentiate into Schwannlike cells in vitro.

Material and methods: Reagents were applied in two different ways (Dezawa inducing method and modified inducing method) in which inducers including $\beta$-mercaptoethanol ( $\beta-M E)$, all-trans-retinoic acid (ATRA), type I collagenase, forskolin, heregulin, basic fibroblast growth factor (BFGF) and brain-derived neurotrophic factor (BDNF) were used in different ways to induce ADSCs of rats to differentiate into Schwann-like cells. After induction, the cell morphologic characteristics and the cellular immunohistochemical staining positive rate of anti-S100 and anti-GFAP (glial fibrillary acidic protein) antibodies and the gray value of immunocytochemical dye with anti-S100 and anti-GFAP antibodies and cell activity measured by the MTT method were compared with each other to evaluate the induction effects. Results: Both methods can induce differentiation of ADSCS of rats into Schwann-like cells, but the cellular morphology of the modified method was more similar to Schwann cells than that of the Dezawa inducing method, there was a higher cellular immunohistochemical staining positive rate and staining grey value in immunocytochemical dye with anti-S100 and antiGFAP antibodies, and less damage in the cell activity of the modified inducing method than that of the Dezawa inducing method.

Conclusions: The effect of the modified method to induce ADSCs to differentiate into Schwann-like cells in vitro is superior to that of the Dezawa inducing method.

Key words: adipose-derived stem cells, Schwann-like cells, MTT, S100, glial fibrillary acidic protein.

\section{Introduction}

Peripheral nerve injury is more frequent in clinical practice. Due to the mature neurons' disability of cell division, the effect of peripheral nerve regeneration after injury was not ideal. At present, tissue engineering provides a new method for peripheral nerve regeneration [1]. As the best seed cells for peripheral nerve tissue engineering, Schwann cells play an important role in peripheral nerve regeneration [2,3], but owing to

\author{
Corresponding author: \\ Songtao Gao \\ Department of Orthopedics \\ The Affiliated Tumor Hospital \\ of Zhengzhou University \\ 127 Dongming Road \\ Zhengzhou, Henan Province \\ 450008, China \\ Phone: +86037165588073 \\ E-mail: gaost2007@163.com
}


the limited source and proliferation ability and the difficulty of cell culture in vitro $[4,5]$, looking for a new method to obtain enough Schwann cells for nerve regeneration was the primary target of the present study.

Adipose-derived stem cells (ADSCS) have the advantages of being easily obtained with an extensive source, easy to cultivate and causing little injury to the donor $[6,7]$. Under certain conditions, ADSCs can differentiate into a variety of tissues such as osseous tissue [8], cartilaginous tissue [9], adipose tissue [10], myoid tissue [11] and nervous tissue [12], so they are ideal seed cells for tissue engineering.

This research intended to isolate and culture the ADSCs of rats and induce the cells to differentiate to Schwann-like cells in vitro by two different methods, so as to provide an effective method of seed cells induction for peripheral nerve tissue engineering.

\section{Material and methods}

\section{Materials}

Adult male Sprague-Dawley rats (provided by the animal experimental center of Zhengzhou University) were used, weighing around 250 g. All animals utilized in this research were cared for according to the policies and principles established by the animal welfare act and the $\mathrm{NIH}$ guide for care and use of laboratory animals. $\beta$-Mercaptoethanol $(\beta-M E)$, all-trans-retinoic acid (ATRA) and type I collagenase (Sigma Chemicals, USA), forskolin (Alexis, Switzerland), heregulin (Neomarker, USA), basic fibroblast growth factor (BFGF) and brain-derived neurotrophic factor (BDNF) (Peprotech, USA) were used for this experiment. The primary antibody of rabbit anti-rat S-100, rabbit anti-rat GFAP and SABC immunohistochemical staining kit (Boster, China), Dulbecco's Modified Eagle Medium (DMEM) of low glucose and fetal bovine serum (Gibco, USA) were used for this experiment.

\section{Methods}

\section{Isolation and culture of ADSCS}

Rats were killed by intraperitoneal anesthesia with $10 \%$ chloral hydrate solution $(0.5 \mathrm{ml} / 100 \mathrm{~g})$. After immersion sterilization in 75\% alcohol, bilateral inguinal fat pads were harvested for experiment under aseptic conditions, minced after washing with phosphate buffer solution (PBS), and dissociated by $0.075 \%$ collagenase type I for $90 \mathrm{~min}$. The solution was passed through a $75 \mu \mathrm{m}$ filter to remove undissociated tissue, then neutralized by the DMEM of low glucose containing $20 \%(\mathrm{v} / \mathrm{v})$ fetal bovine serum and centrifuged at $1000 \times \mathrm{g}$ for $8 \mathrm{~min}$. The stromal cell pellet was resuspended in DMEM of low glucose containing $20 \%(\mathrm{v} / \mathrm{v})$ fetal bovine serum with $1 \%(\mathrm{v} / \mathrm{v})$ penicillin/streptomycin solution, and inoculated in $25 \mathrm{ml}$ culture bottles at a density of $4 \times 10^{5} / \mathrm{ml}$. The media were renewed after 3 to 4 days, and the nonadherent cells were removed. When the cell fusion rate was up to $90 \%$, the cells were passaged with trypsin/EDTA and inoculated in $50 \mathrm{ml}$ culture bottles. Cultures were maintained in a $37^{\circ} \mathrm{C}$ incubator with $5 \% \mathrm{CO}_{2}$. The fourth generation cells were induced to differentiation [13].

\section{Cell induction by two different methods}

DEZAWA method for cell induction - The ADSCS under sub-fused status of the fourth generation were used for induction according to the Dezawa method [14] for inducing bone marrow stromal stem cells to differentiate into Schwann-like cells in vitro: the medium was removed and pre-induction solution (DMEM of low glucose containing 10\% $(\mathrm{v} / \mathrm{v})$ fetal bovine serum and $100 \mu \mathrm{l} / \mathrm{ml}(\beta-M E))$ was added. Cultures were maintained in a $37^{\circ} \mathrm{C}$ incubator with $5 \% \mathrm{CO}_{2}$ for $24 \mathrm{~h}$. The pre-induction solution was removed and washed with PBS 3 times, pre-induction solution (DMEM of low glucose containing $10 \%(\mathrm{v} / \mathrm{v})$ fetal bovine serum and $10 \mu \mathrm{l} / \mathrm{ml}$ ATRA) was added. Cultures were maintained in a $37^{\circ} \mathrm{C}$ incubator with $5 \% \mathrm{CO}_{2}$ for $72 \mathrm{~h}$. The pre-induction solution was removed and washed with PBS 3 times, pre-induction solution (DMEM of low glucose containing $10 \%(\mathrm{v} / \mathrm{v})$ fetal bovine serum and $20 \mu \mathrm{l} / \mathrm{ml}$ forskolin, $400 \mu \mathrm{l} / \mathrm{ml}$ heregulin, $20 \mathrm{ng} /$ $\mathrm{ml} \mathrm{bFGF,} 10 \mathrm{ng} / \mathrm{ml}$ BDNF) was added, cultures were maintained in a $37^{\circ} \mathrm{C}$ incubator with $5 \% \mathrm{CO}_{2}$ for $24 \mathrm{~h}$, then replaced with DMEM of low glucose containing $10 \%(\mathrm{v} / \mathrm{v})$ fetal bovine serum.

Modified method for cell induction - ADSCs under sub-fused status of the fourth generation were used for induction. The medium was removed and pre-induction solution (DMEM of low glucose containing $10 \%(\mathrm{v} / \mathrm{v})$ fetal bovine serum and $50 \mu \mathrm{l} / \mathrm{ml}$ $\beta$-ME, $5 \mu \mathrm{l} / \mathrm{ml}$ ATRA, $10 \mu \mathrm{l} / \mathrm{ml}$ forskolin, $200 \mu \mathrm{l} / \mathrm{ml}$ heregulin, $10 \mathrm{ng} / \mathrm{ml} \mathrm{bFGF}, 5 \mathrm{ng} / \mathrm{ml}$ BDNF) was added, cultures were maintained in a $37^{\circ} \mathrm{C}$ incubator with $5 \% \mathrm{CO}_{2}$ for $24 \mathrm{~h}$, the induction solution was removed and washed with PBS 3 times, replaced with DMEM of low glucose containing $10 \%(\mathrm{v} / \mathrm{v})$ fetal bovine serum for $24 \mathrm{~h}$, then used as the pre-induction solution for $24 \mathrm{~h}$, and replaced with DMEM of low glucose containing $10 \%(\mathrm{v} / \mathrm{v})$ fetal bovine serum.

\section{Comparison of two different induction methods}

Cells of two different induction methods were compared and the undifferentiated cells were used as a control group. 
Growth and differentiation of cells - the growth and morphological change of the two groups were compared.

Immunocytochemical staining and counting - at the same time (the $5^{\text {th }}$ day of the Dezawa method and $7^{\text {th }}$ day of the modified method, same time of every control group), the ADSCs of different groups were digested by $0.25 \%$ trypsin and $0.02 \%$ EDTA, dropped on an aseptic glass slide coated with polylysine after centrifugation and collection, cells were incubated at $37^{\circ} \mathrm{C}$ for $2 \mathrm{~h}$, washed with PBS for $5 \mathrm{~min}$, dried and fixed with $4 \%$ paraformaldehyde, then the cell of all groups were stained by S-100 and GFAP, PBS were used as the first antibody only in the negative control group. Ten visual fields of every slide were observed randomly under light microscopy $(400 \times)$, the positive cell ratio of every 50 cells in a visual field was counted, and the mean gray scale of positive staining area was analyzed by an image analysis system.

Activity of cells by MTT method - ADSCs $(180 \mu \mathrm{l}$ of $1 \times 10^{6} / \mathrm{ml}$ ) of every group were placed in a 96 well culture plate which contained DMEM of low glucose containing $10 \%(\mathrm{v} / \mathrm{v})$ fetal bovine serum, $20 \mu \mathrm{l}$ MTT of $5 \mathrm{mg} / \mathrm{ml}$ was added to each well for $4 \mathrm{~h}$, the liquid were aspirated and $200 \mu \mathrm{l}$ of dimethyl sulfoxide (DMSO) were added on an oscillator for $10 \mathrm{~min}$, and the absorbance of each pore was detected at the wavelength of $490 \mathrm{~nm}$ in an enzyme-linked immunosorbent assay (ELISA) meter.

\section{Statistical analysis}

We analyzed the results by SPSS 10.0, the main statistics method including one-way analysis of variance (ANOVA) which was performed to determine the statistical significance between groups. The $t$-test was used to determine whether the difference between the averages of the data sets was statistically significant. A significance level of $p<0.05$ was used as the cutoff.

\section{Results}

\section{Growth and induction of cells}

The cells of both groups were decreased in volume, shrunken and spindle-shaped after induction, the cubic configuration of the cell was more obvious than before, a hyperlucent zone and 2 or 3 slender processes surrounded the cell body, then cells continued to shrink into slender processes, the processes were more slender than before and morphology of cells was similar to Schwann cells, and the cell nuclei were round and located on one side of the cell body. There were no morphological changes of the control group (Figure $1 \mathrm{~A}-\mathrm{C}$ ). After induction, there were more necrotic cells and lower cellular plating density of the Dezawa method compared with that of the modified method. The cells of the modified method grew more rapidly than the cells of the Dezawa method.

\section{Immunocytochemical staining and counting}

After being stained by S-100 and GFAP, the cytoplasm of the positive staining cells was dyed yellow. The morphology of positive staining cells was consistent with that of living cells observed under an inverted microscope. The undifferentiated cells of the control group showed negative staining, i.e. they had no expression of S-100 and GFAP. The staining intensity of S-100 and GFAP of cells in the modified method is more strongly positive than that of cells in the Dezawa method (Figure $1 \mathrm{D}-1$ ). In cells of the modified method, the staining positive ratio and gray value of S-100 were $67.3 \pm 5.1 \%$ and $95.3 \pm 4.81$; the staining positive ratio and gray value of GFAP were $65.5 \pm 5.8 \%$ and $94.71 \pm 4.14$. In cells of the Dezawa method, the staining positive ratio and gray value of S-100 were $57.2 \pm 4.5 \%$ and $121.21 \pm 4.32$; the staining positive ratio and gray value of GFAP were $54.2 \pm 4.2 \%$ and $123.44 \pm 4.18$. The staining positive ratio and gray value of S-100 and GFAP of the modified method were superior to those of the Dezawa method; there was a significant difference between them $(p<0.05)$ (Table I).

\section{Activity of cells by MTT method}

There was no significant difference of cell activity between the control group $(6.12 \pm 0.35)$ and the modified method $(5.36 \pm 0.41)(p>0.05)$, but there was a significant difference between the Dezawa method $(5.83 \pm 0.21)$ and the modified method $(p<0.05)$ (Table I)

\section{Discussion}

The ADSC is a kind of multipotent stem cell originating from adipose tissue. It possesses morphology and multilineage differentiation potential similar to bone marrow stromal stem cells (BMSCs) $[15,16]$. Compared with BMSCs, the extensive sources and superficial location of subcutaneous adipose tissue, and abundant cells easily obtained from waste adipose tissue (about $1 \times 10^{9}$ stem cells from $10 \mathrm{ml}$ of adipose tissue) without complicated anesthesia and operation, and low incidence of infection to the donor are the advantages of ADSCs. In addition, the culture conditions of ADSCs are not as strict as those required for BMSCs, and the ADSCs possess strong capacity for proliferation (average passage time about $60 \mathrm{~h}$ ) and stable multiplication ratio for 13-15 generations. Furthermore, the proportions of aging and dead cells during cell proliferation are low [17], so ADSCs are gradually becoming an optimum selection for seed cells of tissue engineering. 


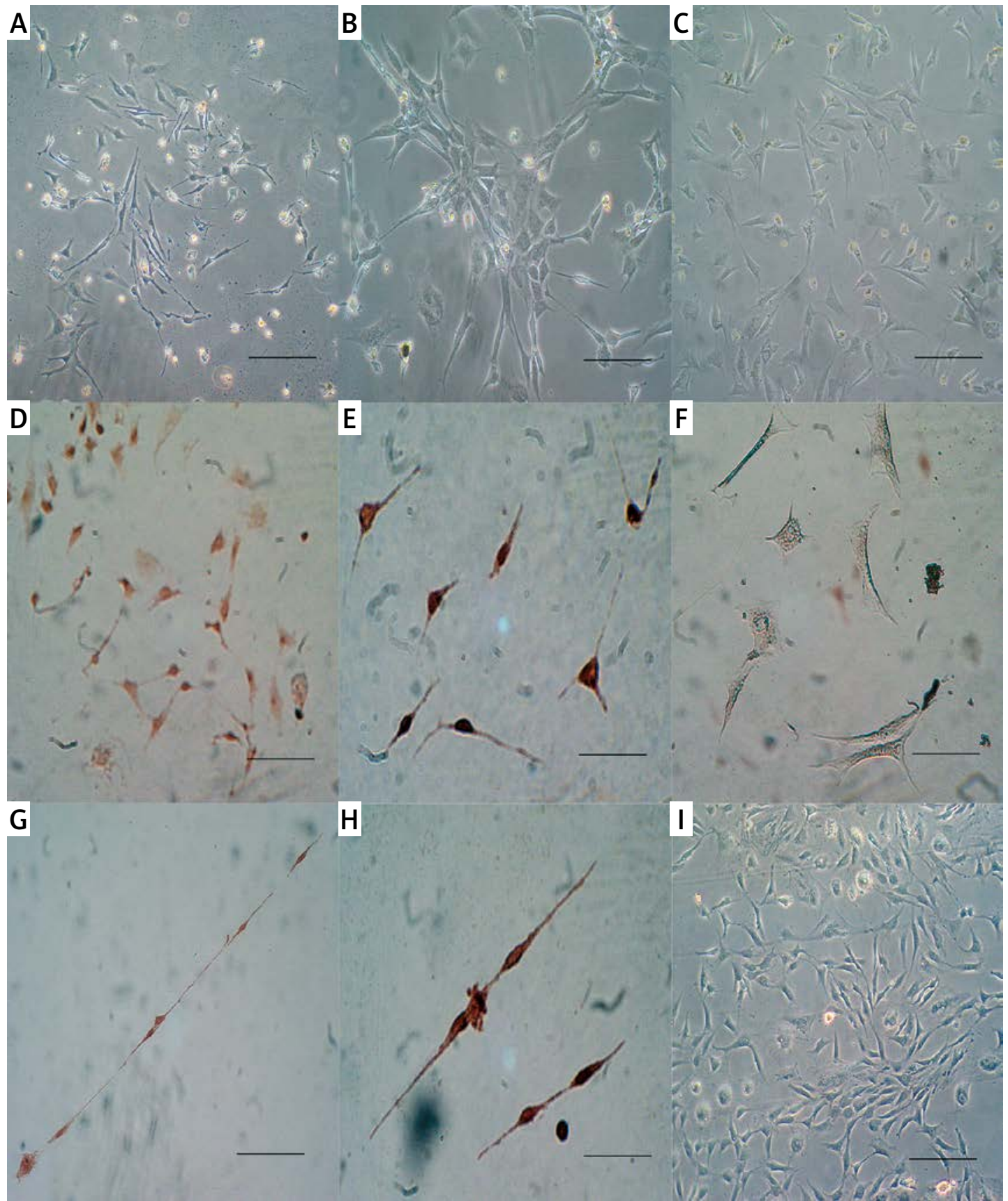

Figure 1. A, B - The cells of Dezawa and modified method showed shrinkage with spindle shape, the cubic configuration of cells was more obvious, and morphology of cells was similar to Schwann cells. Magnification 200x and scale bar is 100 for A, magnification 400x and scale bar is 50 for B. C - There were no morphological changes of the control group. Magnification 200x and scale bar is 100. D - Immunocytochemical staining of GFAP in cells of Dezawa method. Magnification 200x and scale bar is 100. E - Immunocytochemical staining of GFAP in cells of modified method, staining intensity of cells was more strongly positive than that of cells in Dezawa method. Magnification $400 \times$ and scale bar is 50 . F - Cells of control group (undifferentiated cells). Magnification 400x and scale bar is 50. G - Immunocytochemical staining of S-100 in cells of Dezawa method. Magnification 400x and scale bar is $50 . \mathbf{H}-$ Immunocytochemical staining of S-100 in cells of modified method, staining intensity of cells was more strongly positive than that of cells in Dezawa method. Magnification 400x and scale bar is 50. I - Cells of control group (undifferentiated cells). Magnification 200x and scale bar is 100

Adipose-derived stem cells can differentiate into neural cells under the appropriate inducing conditions. Ferroni et al. [18] found that ADSCs can expressing nestin, glial fibrillary acidic protein (GFAP) and neuronal nuclear protein (NeuN) under induc- tion of valproic acid, butylated hydroxyanisole, insulin and hydrocortisone, confirmed by Western blot. Other research showed that murine ADSCS can express the protein phenotype of neuron or glia cells under the use of inducers in vitro [19]. 
Table I. Comparison of staining positive ratio and gray value in different groups $(x \pm \mathrm{s}, n=10)$

\begin{tabular}{|c|c|c|c|}
\hline Variable & S-100 & GFAP & MTT \\
\hline \multicolumn{4}{|l|}{ Dezawa method: } \\
\hline Staining positive ratio & $57.2 \pm 4.5 \%$ & $54.2 \pm 4.2 \%$ & $5.83 \pm 0.21^{\ddagger}$ \\
\hline Gray value & $121.21 \pm 4.32$ & $123.44 \pm 4.18$ & \\
\hline \multicolumn{4}{|l|}{ Modified method: } \\
\hline Staining positive ratio & $67.3 \pm 5.1 \%^{*}$ & $65.5 \pm 5.8 \%^{*}$ & $5.36 \pm 0.41^{\#}$ \\
\hline Gray value & $95.3 \pm 4.81^{*}$ & $94.71 \pm 4.14^{*}$ & \\
\hline \multicolumn{4}{|l|}{ Control group: } \\
\hline Staining positive ratio & 0 & 0 & $6.12 \pm 0.35$ \\
\hline Gray value & 0 & 0 & \\
\hline
\end{tabular}

${ }^{\star}$ Compared with Dezawa method, $p<0.05,{ }^{\ddagger}$ compared with control group, $p<0.05,{ }^{\#}$ compared with control group, $p>0.05$.

Owing to the complexity of orientational differentiation of stem cells and because the effect of a variety of inducers used at the same time is better than that used one by one, we changed the Dezawa inducing method in which single inducers are used several times to one in which combined inducers are used several times.

$\mathrm{S}-100$ is a kind of acid calcium binding protein, and GFAP is a kind of intermediate filament protein; both of them exist in Schwann cells. Gray scale is a transparent degree index of translucent medium. Its value is divided into 0 to 256 grades and is inversely proportional to the strength of the positive immunohistochemical reaction product. The result shows that the staining positive ratio and gray scale of S-100 and GFAP in Schwann-like cells of the improved inducing method were superior to those of the Dezawa inducing method, which means that the induction effect of the former was better than that of the latter. $\beta$-mercaptoethanol ( $\beta-M E)$ is an antioxidant that increases intracellular cyclic adenosine monophosphate (CAMP) and prevents the peroxide from causing damage to cells and promotes adhesion and proliferation of stem cells. It was shows that $\beta$-ME can protect neurons in serum-free medium and improved the growth of neuritis [20]. It was also shown that $\beta-M E$ promotes neural differentiation of stem cells [21]; the principle was to accelerate glutathione synthesis and reduce the cell response to oxygen tension. At the same time, the increase of the concentration of intracellular CAMP can promote axonal elongation, probably owing to the activation of protein kinase A (PKA) or the p38 signal pathway originated by CAMP.

Forskolin is an adenylate cyclase activator which can increase the intracellular CAMP content and improve the cells' response to neurotrophic factor. Kim et al. [22] found that forskolin could induce the glial cell differentiation of neural stem cells through activation of the PKA signal pathway or increase the concentration of intracellular CAMP.
All-trans retinoic acid (ATRA) is critical for the development, growth and essential physiological activities of vertebrates. A certain concentration of ATRA can promote cell proliferation, differentiation and maturation. Disorders of ATRA might not only cause malformations and genetic mutations in a mouse embryo, but also induce the differentiation and gene expression of human teratocarcinoma cells. It has a strong promotability in mitogenesis and differentiation mainly through the cell surface receptors RARs and RXRs, and also regulating the expression of some encoding factors, which is very important for the early differentiation of neural cells [23]. Research shows that the receptor of ATRA exists in the nucleus. All-trans retinoic acid combines with the receptor in chromatin, then regulates a series of gene expression and changes the phenotype and differentiation of cells after entering the cell [24].

Heregulin is a subtype of neuregulin. Neuregulin is a neural gene regulator and an important axon-derived signal which can prevent apoptosis of Schwann cell precursors and selectively induce neural crest cells to differentiate into Schwann cells through a signaling system. During this process, the main function of neuregulin-1 is participation in the differentiation of glial cells, regulation and control of the formation of myelin sheath and Schwann cells $[25,26]$.

The bFGF is a kind of polypeptide factor that promotes the growth of cells and mitogen of glia cells. It promotes the proliferation and differentiation of glia cells and neuronal precursor cells, plays an important role in the early development of the nervous system and has a nutritional role in neurons. BFGF also promotes cell differentiation and decides the direction of differentiation in vitro. It promotes proliferation of multipotent neural stem cells that can differentiate into neurons and glia cells. Qian et al. [27] found that the proliferation or differentiation of neural stem 
cells of embryonic brain was dependent on the concentration of bFGF: the cellular mitogenic signal was initiated under low concentration of bFGF, while the cellular mitogenic and differentiation signals were initiated under high concentration of bFGF.

The BDNF is a kind of neuronal protective agent, and its mechanism is probably related to the inductive effect on the upregulation of TrkB mRNA. Its signal transduction pathway begins with receptor tyrosine phosphorylation and finishes with the Ras-MAPK pathway. The BDNF can activate the signaling pathways (including the pathway of $G$ protein and protein kinase $C$ ) through tyrosine kinase receptor $\mathrm{B}$, so as to promote neural stem cells to differentiate to glia cells [28]; this process is probably related to its binding to the receptor in stem cell membrane and activation of mitogen-activated protein kinase.

Through the MTT method in the research, we found that the activity of cells in the modified method was enhanced when compared with cells in the Dezawa method when the dosage and induction time of the inducer were decreased, the probable reasons including the following: Firstly, the small amount of inducer has less effect on the activity of cells; secondly, the time interval between application of different inducers in the modified method was $24 \mathrm{~h}$, so the damage of some cells caused by the inducer can be repaired and the activity of cells were improved, which more conform to the growth cycle of cells. This modified method of inducer application probably provided a more effective method to induce ADSCs to differentiate into Schwann-like cells in vitro.

In conclusion, although we have induced the rat ADSCs to differentiate into Schwann-like cells in vitro successfully, owing to a lack of specific molecular markers for identification of the adult stem cells [29], there were still some limitations in identification of the cellular differentiation effect only depending on the morphology and specific marker of cells. Hence further research on the induction mechanism and expression of cell function is required.

\section{Conflict of interest}

The authors declare no conflict of interest.

\section{References}

1. Angius D, Wang H, Spinner RJ, Gutierrez-Cotto Y, Yaszemski MJ, Windebank AJ. A systematic review of animal models used to study nerve regeneration in tissue-engineered scaffolds. Biomaterials 2012; 33: 8034-9.

2. Jain S, Sharma A, Basu B. In vitro cytocompatibility assessment of amorphous carbon structures using neuroblastoma and Schwann cells. J Biomed Mater Res B Appl Biomater 2013; 101: 520-31.
3. Kashani IR, Golipoor Z, Akbari M, et al. Schwann-like cell differentiation from rat bone marrow stem cells. Arch Med Sci 2011; 7: 45-52.

4. Wakao S, Hayashi T, Kitada M, et al. Long-term observation of auto-cell transplantation in non-human primate reveals safety and efficiency of bone marrow stromal cell-derived Schwann cellsin peripheral nerve regeneration. Exp Neurol 2010; 223: 537-47.

5. Diaz Quiroz JF, Echeverri K. Spinal cord regeneration: where fish, frogs and salamanders lead the way, can we follow? Biochem J 2013; 451: 353-64.

6. Zavan B, Michelotto L, Lancerotto L, et al. Neural potential of a stem cell population in the adipose and cutaneous tissues. Neurol Res 2010; 32: 47-54.

7. Heidari B, Shirazi A, Akhondi MM, et al. Comparison of proliferative and multilineage differentiation potential of sheep mesenchymal stem cells derived from bone marrow, liver, and adipose tissue. Avicenna J Med Biotechnol 2013; 5: 104-17.

8. Mehrkens A, Saxer F, Güven S, et al. Intraoperative engineering of osteogenic grafts combining freshly harvested, human adipose-derived cells and physiological doses of bone morphogenetic protein-2. Eur Cell Mater 2012; 24: 308-19.

9. He F, Pei M. Extracellular matrix enhances differentiation of adipose stem cells from infrapatellar fat pad toward chondrogenesis. J Tissue Eng Regen Med 2013; 7: 73-84.

10. Butala P, Hazen A, Szpalski C, Sultan SM, Coleman SR, Warren SM. Endogenous stem cell therapy enhances fat graft survival. Plast Reconstr Surg 2012; 130: 293-306.

11. Carvalho PH, Daibert AP, Monteiro BS, et al. Differentiation of adipose tissue-derived mesenchymal stem cells into cardiomyocytes. Arq Bras Cardiol 2013; 100: 82-9.

12. Pavlova G, Lopatina T, Kalinina N, et al. In vitro neuronal induction of adipose-derived stem cells and their fate after transplantation into injured mouse brain. Curr Med Chem 2012; 19: 5170-7.

13. Ma Y, Li Q, Zhao DQ, et al. Isolation, cultivation of adipose-derived mesenchymal stem cells and its chondrogenic ability. Xi Bao Yu Fen Zi Mian Yi Xue Za Zhi 2007; 23: 463-5.

14. Dezawa M, Takahashi I, Esaki M, Takano M, Sawada H. Sciatic nerve re-generation in rats induced by transplantation of in vitro differentiated bone-marrow stromal cells. Eur J Neurosci 2001; 14: 1771-6.

15. Marappagounder D, Somasundaram I, Dorairaj S, Sankaran RJ. Differentiation of mesenchymal stem cells derived from human bone marrow and subcutaneous adipose tissue into pancreatic islet-like clusters in vitro. Cell Mol Biol Lett 2013; 18: 75-88.

16. Liu GB, Cheng YX, Feng YK, et al. Adipose-derived stem cells promote peripheral nerve repair. Arch Med Sci 2011; 7: 592-6.

17. Bai X, Pinkernell K, Song YH, Nabzdyk C, Reiser J, Alt E. Genetically selected stem cells from human adipose tissue express cardiac markers. Biochem Biophys Res Commun 2007; 353: 665-71.

18. Ferroni L, Gardin C, Tocco I, et al. Potential for neural differentiation of mesenchymal stem cells. Adv Biochem Eng Biotechnol 2013; 129: 89-115.

19. Safford KM, Safford SD, Gimble JM, Shetty AK, Rice HE. Characterization of neuronal/glial differentiation of murine adipose-derived adult stromal cells. Exp Neurol 2004; 187: 319-28.

20. Jiang L, Zhu JK, Liu XL, Xiang P, Hu J, Yu WH. Differentiation of rat adipose tissue-derived stem cells into Schwannlike cells in vitro. Neuroreport 2008; 19: 1015-9. 
21. Liu H, Xue WJ, Xie YF, Feng XS, Huo FQ. Tea polyphenol-induced neuron-like differentiation of mouse mesenchymal stem cells. Chin J Physiol 2011; 54: 111-7.

22. Kim BJ, Kim SS, Kim YI, Paek SH, Lee YD, Suh-Kim H. Forskolin promotes astroglial differentiation of human central neurocytoma cells. Exp Mol Med 2004; 36: 52-6.

23. Ghoochani A, Shabani K, Peymani M, et al. The influence of peroxisome proliferator-activated receptor gamma(1) during differentiation of mouse embryonic stem cells to neural cells. Differentiation 2012; 83: 60-7.

24. Montiel-Eulefi E, Nery AA, Rodrigues LC, Sánchez R Romero $\mathrm{F}$, Ulrich $\mathrm{H}$. Neural differentiation of rat aorta pericyte cells. Cytometry A 2012; 81: 65-71.

25. Jessen KR, Mirsky R. Negative regulation of myelination: relevance for development, injury, and demyelinating disease. Glia 2008; 56: 1552-65.

26. Triolo D, Dina G, Taveggia C, Vaccari I, et al. Vimentin regulates peripheral nerve myelination. Development 2012; 139: 1359-67.

27. Qian X, Davis AA, Goderie SK, Temple S. FGF2 concentration regulates the generation of neurons and glia from multipotent cortical stem cells. Neuron 1997; 18: 81-93.

28. Cheng A, Coksaygan T, Tang H, et al. Truncated tyrosine kinase B brain-derived neurotrophic factor receptor directs cortical neural stem cells to a glial cell fate by a novel signaling mechanism. J Neurochem 2007; 100: 1515-30.

29. Safwani WK, Makpol S, Sathapan S, Chua K. Impact of adipogenic differentiation on stemness and osteogenic gene expression in extensive culture of human adipose-derived stem cells. Arch Med Sci 2014; 10: 597-606. 